\title{
Astrócitos imunorreativos à proteína glial fibrilar ácida (GFAP) em sistema nervoso central de equinos normais e de equinos com leucoencefalomalácia ${ }^{1}$
}

\author{
Karen Regina Lemos ${ }^{2}$ e Antonio Carlos Alessi ${ }^{3}$
}

\begin{abstract}
Lemos K.R. \& Alessi A.C. 1999. [Glial fibrillary acidic protein (GFAP) immunoreactive astrocytes in the Central Nervous System of normal horses and horses with leukoencephalomalacia.] Astrócitos imunorreativos à proteína glial fibrilar ácida (GFAP) em sistema nervoso central de equinos normais e de equinos com leucoencefalomalácia. Pesquisa Veterinária Brasileira 19(3/4):104-108. Depto Patologia Veterinária, Faculdade de Ciências Agrárias e Veterinárias, Unesp, Rod. Carlos Tonanni Km 5, Jaboticabal, SP 14870-000, Brazil.

The glial fibrillary acidic protein (GFAP), subunit of the intermediary filaments of the cellular cytoskeleton, exists in the cytoplasm of astrocytes. Immunohistochemistry utilizing primary antibodies anti-GFAP is generally chosen to identify astrocytes in the central nervous system (CNS), allowing also to verify their hypertrophy. Several studies show the distribution, morphology and cytoarchitecture of the astrocytes in several areas of the CNS of humans and laboratory animals. However, in domestic animals, especially in horses, little information is available. In the present study the density and morphology of GFAP-immunoreactive astrocytes in the white matter of the cerebral cortex of horses with leukoencephalomalacia (LEM) has been compared with such aspects in normal horses. In animals with LEM hypertrophic astrocytes in areas close to the lesions were observed. There was enlargement of the perikarion, nucleus and the cytoplasmic extension. The astrocytes were reduced in number and the immunoreactivity was increased. In the normal animals constant distribution of immunoreactive cells characteristic of fibrous astrocytes was seen. Vascular changes in the animals with LEM, as for example degeneration of vascular endothelium, were also observed and could be correlated with the astrocytic alterations.
\end{abstract}

INDEX TERMS: Astrocytes, GFAP, horse, leukoencephalomalacia.

RESUMO.- A proteína glial fibrilar ácida (GFAP), subunidade dos filamentos intermediários do citoesqueleto celular, está presente no citoplasma de astrócitos. Técnicas imunohistoquímicas com anticorpos primários anti-GFAP são geralmente empregadas para identificar astrócitos no sistema nervoso, permitindo verificar também sua hipertrofia. Vários estudos mostram a distribuição, a morfologia e a citoarquitetura de astrócitos em várias regiões do SNC do homem e de animais de laboratório. No entanto, em animais domésticos e, especialmente em equinos, poucas informações estão disponíveis.

\footnotetext{
${ }^{1}$ Aceito para publicação em 2 de julho de 1998.

${ }^{2}$ Médica Veterinária, Mestre em Medicina Veterinária, Unesp - Faculdade de Ciências Agrárias e Veterinárias, FCAV.

${ }^{3}$ Professor Adjunto, Depto Patologia Veterinária, Unesp - FCAV, Rod. Carlos Tonanni Km 5, Jaboticabal, SP 14870-000.
}

No presente trabalho, verificou-se a densidade e a morfologia de astrócitos imunorreativos à GFAP na substância branca da córtex cerebral de equinos com leucoencefalomalácia (LEM) comparando-se esses aspectos com o de equinos normais. Animais com LEM apresentaram hipertrofia de astrócitos em áreas próximas às lesões, representada pelo aumento do corpo celular, do núcleo e dos prolongamentos citoplasmáticos. O número de astrócitos apresentou-se reduzido e a imunorreatividade foi mais acentuada. Nos animais normais, verificouse distribuição constante de astrócitos imunorreagentes com características de fibrosos. Alterações vasculares nos animais com LEM, como por exemplo degeneração de endotélio vascular, também foram observadas, podendo estar associadas às alterações astrocíticas.

TERMOS DE INDEXAÇÃO: Astrócito, GFAP, equino, leucoencefalomalácia. 


\section{INTRODUÇÃO}

Os recentes avanços em técnicas de cultivo celular e também o aprimoramento de técnicas que permitem identificação mais específica de astrócitos, resultaram em um aumento significativo no conhecimento sobre essa importante célula da macroglia. Estudos sobre o desenvolvimento embrionário, morfologia, funções e participação de astrócitos em processos patológicos têm sido frequentes ultimamente (Montgomery 1994).

Astrócitos são importantes por fornecerem suporte nutricional e estrutural para neurônios, por participarem funcionalmente da barreira hemato-encefálica (Bignani 1991) e por participarem de outras funções propostas tais como detoxificação, fagocitose, funções imunes e outras (revisado por Montgomery 1994).

Em processos patológicos, os astrócitos respondem prontamente, e, por outro lado, alterações celulares em astrócitos são indicadores confiáveis de lesão do sistema nervoso central (SNC) (Lantos 1990, Malhotra et al. 1990).

A identificação histológica de astrócitos normais ou em situação patológica tem sido feita através de método imunoistoquímico que detecta antígenos da proteína glial fibrilar ácida (GFAP), componente dos filamentos de tamanho intermediário do citoesqueleto celular, presente nos astrócitos e em algumas outras células (Eng \& Ghirnikar 1994, Cullen 1997). A expressão de GFAP, por si só, deve ser considerada nas diferentes situações (Eng \& Ghirnikar 1994). Por exemplo, em certas lesões a imunorreatividade a essa proteína é maior devido à melhor preservação frente aos fixadores (Cullen 1997).

A distribuição de astrócitos imunorreativos à GFAP em SNC têm sido estudada em diversas situações. Kálman \& Hajós (1989) e Hajós \& Kálman (1989) realizaram um minucioso mapeamento de astrócitos imunorreativos à GFAP em ratos normais. Estudos semelhantes foram realizados em marmotas (McDermott \& Lantos 1989), ovinos (Jeffrey et al. 1990), em codornas japonesas (Cameron-Curry 1991), em equinos com mielopatia compressiva (Yovich et al. 1991) e em bovinos normais ou com raiva (Machado \& Alessi 1997). Em outras situações experimentais e também no homem, em alguns processos patológicos, o estudo da distribuição e da morfologia de astrócitos imunorreativos à GFAP têm se mostrado útil ao diagnóstico e tem contribuído para o conhecimento da importância da astrogliose (Eng \& Ghirnikar 1994). Por outro lado, a função da GFAP em astrócitos não é clara. Camundongos geneticamente transformados para ausência de GFAP, crescem e se reproduzem normalmente (Pekny 1995).

A literatura veterinária é pobre em informações sobre a participação de astrócitos na patogênese de doenças naturais do SNC que afetam as diversas espécies animais (Montgomery 1994). Assim, o presente trabalho, teve como objetivo investigar a distribuição de astrócitos imunorreativos à GFAP na substância branca da cortex cerebral de equinos normais e também de equinos com leucoencefalomalácia (LEM) causada por ingestão de alimento contaminado com micotoxina.

\section{MATERIAL E MÉTODOS}

Animais

Os encéfalos de oito equinos normais adultos (Grupo N), machos e fêmeas, sem raça definida, foram obtidos junto ao Frigorífico de Equinos, em Araguari, MG). Os animais foram dessensibilizados por concussão e a sangria foi feita pela seção dos vasos cervicais.

Oito equinos adultos com LEM (Grupo L), machos e fêmeas, de diferentes raças puras ou cruzadas, foram obtidos no Departamento de Patologia Veterinária da Faculdade de Ciências Agrárias e Veterinárias, Universidade Estadual Paulista, durante o período de agosto de 1992 a outubro de 1994, de animais provenientes de várias regiões dos Estados de São Paulo e de Minas Gerais, onde ocorrera surtos da enfermidade. Em todos os casos, a contaminação foi com milho mofado. $O$ diagnóstico foi confirmado com base em dados epidemiológicos, clínicos e anatomopatológicos (Riet-Correa et al. 1982).

Processamento do material

Os encéfalos foram fixados em solução de formol a $10 \%$, tamponado com fosfatos, $\mathrm{pH} 7,2$, durante oito dias.

Fragmentos de córtex cerebral de equinos dos dois grupos foram incluídos em parafina. Cortes de 4 a $5 \mathrm{~mm}$ de espessura foram montados em lâminas de vidro que recebiam, previamente, uma fina camada de Poly-L-lisina (Sigma P-1399), diluído a 0,01\%, em forma de um esfregaço.

\section{Imunohistoquímica}

Cortes desparafinados foram reidratados e incubados com metanol (50\%) acrescido de peróxido de hidrogênio a 3\%, para inibição da peroxidase endógena. Em sequência, cortes foram lavados em PBS e incubados com tripsina $0,1 \%$ diluída em PBS, durante 25 minutos, a $37^{\circ} \mathrm{C}$. As lâminas foram então lavadas em PBS e incubadas com anticorpo policlonal anti-GFAP (DAKO Z-334), diluído a 1:300, durante um pernoite, em geladeira. Soro de coelho normal foi utilizado como controle negativo. Em seguida foram lavadas em PBS, incubadas com anticorpo de ligação (ovino anti-lgG de coelho; SIGMA R-6503) diluído a 1:25, durante 30 minutos, lavadas novamente e incubadas com complexo PAP (SIGMA P-2026) 1:200, durante 30 minutos. No próximo passo, lâminas foram lavadas em PBS e incubadas com diaminobenzidina (SIGMA D-9015) 0,03\% acrescido de peróxido de hidrogênio $0,03 \%$, por um período de 5 a 8 minutos, sob controle microscópico da intensidade da reação cromógena. Depois, as lâminas foram lavadas em água corrente, desidratadas em álcool e montadas com lamínula.

\section{Morfometria}

Utilizou-se o Sistema Analisador de Imagens Video Plan (Kontron Elektronik/Zeiss) em microscópio óptico binocular com objetiva de 40x.

Foram medidos manualmente, contornando-se com o mouse, a área do corpo celular e o comprimento dos três maiores prolongamentos citoplasmáticos de 12 células imunorreativas por animal, localizadas em regiões próximas às lesões nos equinos com LEM e regiões correspondentes nos equinos normais.

\section{Densitometria}

A densidade de astrócitos imunorreativos à GFAP (célula/área) foi mensurada utilizando-se uma lente ocular integradora com uma área de $1,21 \mathrm{~mm}^{2}$, em conjunto com lente objetiva de $25 x$. Obtiveramse doze leituras de cada animal, nos oito animais de cada grupo $\mathrm{N} \mathrm{e}$ L. Calculou-se a média aritmética de cada grupo e seu respectivo desvio padrão. 


\section{RESULTADOS}

A técnica imunohistoquímica empregada, utilizando complexo PAP, identificou com sucesso os elementos estruturais com antígeno GFAP, principalmente astrócitos. A morfologia característica dos astrócitos foi facilmente visualizada, devido à coloração marrom de seu citoplasma, resultado positivo da imunohistoquímica, contrastante com o roxo azulado do seu núcleo, corado pela hematoxilina.

A análise da substância branca da córtex cerebral dos animais normais, mostrou presença constante de astrócitos imunorreativos com características de fibrosos (Fig. 1 e 2). Pelo método densitométrico empregado, obteve-se o valor de 11,7 células por $\mathrm{mm}^{2}$. A área celular média foi de 23,6 $\mathrm{mm}^{2}$, com núcleo medindo em média $11,6 \mathrm{~mm}^{2}$. O maior e o menor diâmetros médios foram de 5,2 e 3,1 mm, respectivamente (Quadro 1). Esses núcleos eram aparentemente pequenos, algumas vezes mostravam nucléolos. Outras vezes, a coloração intensa do citoplasma e o posicionamento impedia a visualização do núcleo. Os prolongamentos se apresentaram finos com ramificações delicadas. A média de comprimentos dos três maiores prolongamentos foi de $41,0 \mathrm{~mm}$. Processos citoplasmáticos de astrócitos localizados próximos a vasos sangüíneos projetavam-se em direção a esses e, ao redor dos vasos, a reação mostrava aglomerado de processos podais terminais.

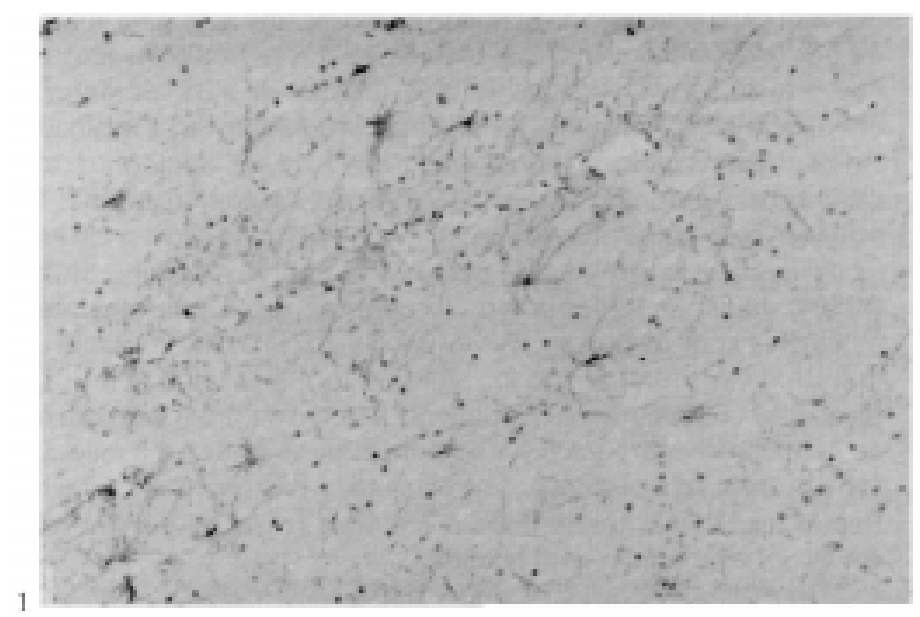

Fig. 1. Astrócitos fibrosos com núcleo pequeno e processos citoplasmáticos finos e longos, na substância branca da córtex cerebral de equino normal. PAP, obj. $20 \mathrm{x}$.

Fig. 2. Idem à anterior. PAP, obj. 40x.

Fig. 3. Astrócitos com corpo celular e núcleo aumentados e processos evidentes, na substância branca da córtex cerebral de equino com leucoencefalomalácia. PAP, obj. 40x.
Quadro 1. Morfometria e densitometria de astrócitos imunorreativos à GFAP na substância branca da córtex cerebral de equinos clinicamente normais e de equinos com leucoencefalomalácia, Jaboticabal (SP), 1995

\begin{tabular}{lrlrl}
\hline & Normal $(\mathrm{n}=8)$ & \multicolumn{2}{c}{ LEM $(\mathrm{n}=8)$} \\
\hline Área do corpo celular $\left(\mu \mathrm{m}^{2}\right)$ & 23,6 & $\pm 3,49$ & 55,0 & $\pm 7,53 *$ \\
Área nuclear $\left(\mu \mathrm{m}^{2}\right)$ & 11,6 & $\pm 3,81$ & 33,4 & $\pm 13,13 *$ \\
Maior diâmetro nuclear $(\mu \mathrm{m})$ & 5,2 & $\pm 0,97$ & 8,6 & $\pm 1,99 *$ \\
Menor diâmetro nuclear $(\mu \mathrm{m})$ & 3,1 & $\pm 0,68$ & 5,4 & $\pm 1,22 *$ \\
Comprimento prolongamentos $(\mu \mathrm{m})$ & 41,0 & $\pm 20,60$ & 55,6 & $\pm 21,22 \mathrm{~ns}$ \\
Número de células/mm2 & 11,7 & $\pm 2,97$ & 8,5 & $\pm 2,20 *$ \\
& & & &
\end{tabular}

Nos equinos com leucoencefalomalácia observou-se densidade de astrócitos de 9,5 células por $\mathrm{mm}^{2}$ e média de área de corpo celular de $55,0 \mathrm{~mm}^{2}$ (Quadro 1). Esses astrócitos mostravam-se também intensamente corados em marrom, indicando forte imunorreatividade (Fig. 3, 4 e 5). O núcleo tendia a se apresentar maior, acompanhando o aumento de volume celular. O nucléolo tornava-se mais visível (Fig. 6). A média da área nuclear nesse grupo foi de $73,4 \mathrm{~mm}^{2}$. As medidas de maior e menor diâmetros também acompanharam a área nuclear, sendo de 8,6 e $5,4 \mathrm{~mm}$, respectivamente. Os processos astrocíticos apresentavam-se mais espessos, no entanto, as suas ramificações não eram nítidas, principal-
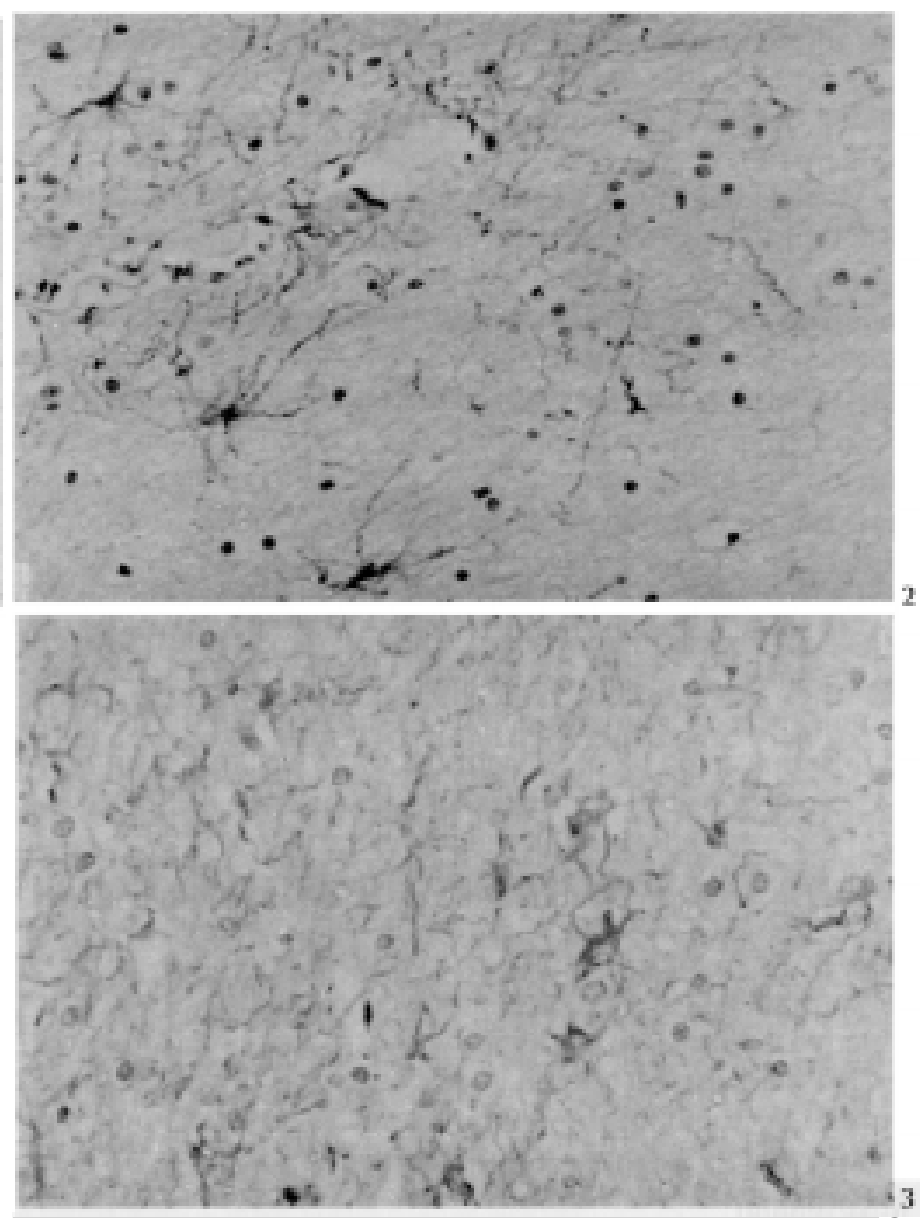

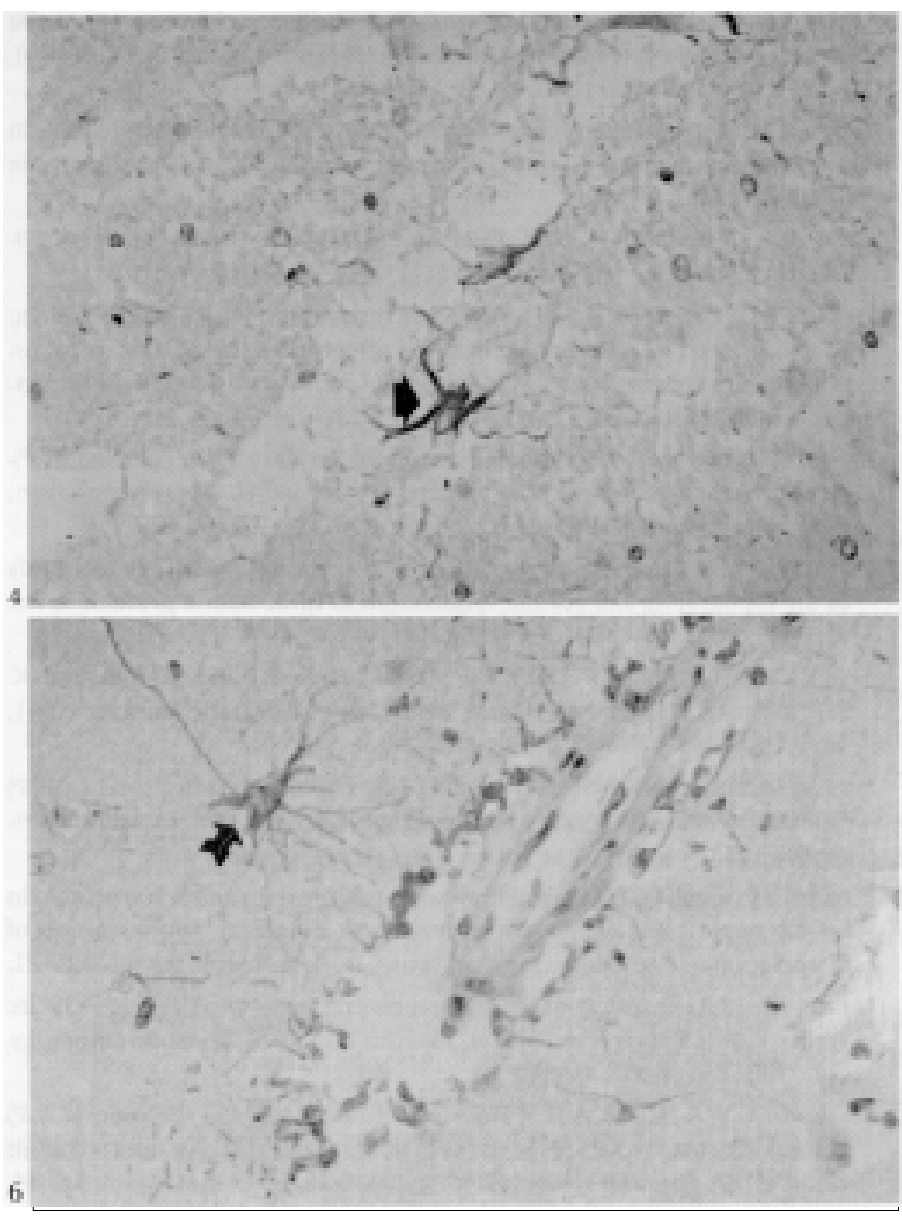

Fig. 4. Astrócitos com corpo celular e núcleo aumentados e processos espessados, na substância branca da córtex cerebral de equino com leucoencefalomalácia. PAP, obj. 40x.

Fig. 6. Astrócito (seta) com corpo celular e núcleo aumentados, nucléolo evidente e processos direcionados ao vaso sanguíneo, na substância branca da córtex cerebral de equino com leucoencefalomalácia. PAP, obj. 40x.

mente nas regiões onde ocorria necrose (Fig. 4). O comprimento desses prolongamentos no grupo $L$ foi maior $(55,6$ $\mathrm{mm}$ ) que o verificado nos equinos normais $(41,0 \mathrm{~mm})$. Outras alterações verificadas foram principalmente aquelas associadas aos vasos sanguíneos, incluindo degeneração de células endoteliais (Fig. 7), edema (Fig. 5) e hemorragia perivasculares.

\section{DISCUSSÃO}

Embora a distribuição e a morfologia de astrócitos em diferentes espécies animais não apresente diferenças fundamentais quando em situação normal, em condições patológicas tem-se observado importantes alterações. Maior imunorreatividade pode ser previsível em vista de hipertrofia de astrócitos. No entanto, nem sempre se verifica aumento da quantidade de GFAP intracitoplasmático quando determinado por métodos quantitativos (Eng et al. 1992). Mas o estudo
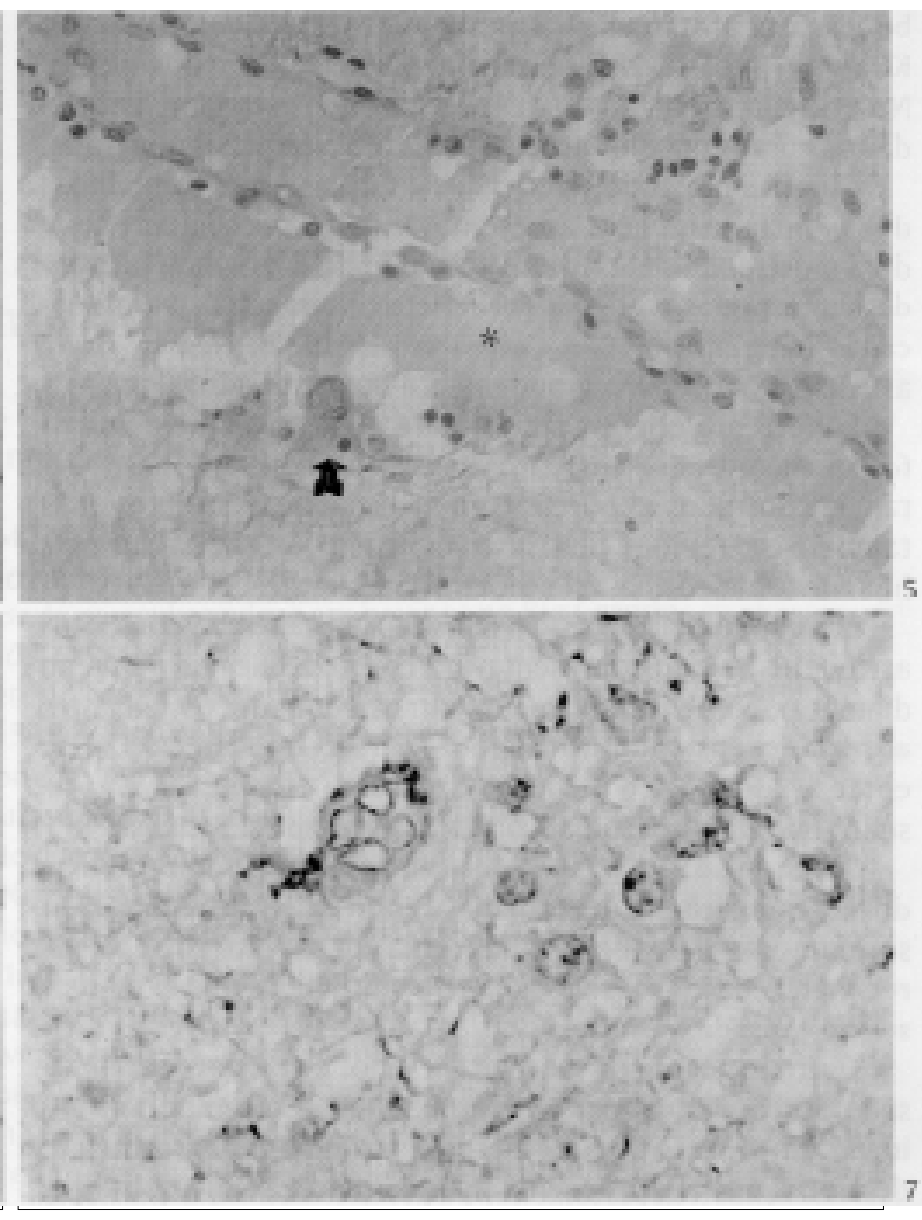

Fig. 5. Astrócito hipertrofiado (seta) junto a vaso sanguíneo com edema periférico (*), na substância branca da córtex cerebral de equino com leucoencefalomalácia. PAP, obj. 40x.

Fig. 7. Vaso sanguíneo com células endoteliais aumentadas e processos astrocíticos ao redor (seta), na substância branca da córtex cerebral de equino com leucoencefalomalácia. PAP, obj. 40x.

de astrócitos imunorreativos fornece informações mais precisas em relação ao seu estado funcional (Montgomery 1994). A melhoria das técnicas que desmascaram os determinantes antigênicos da GFAP com uso de enzimas, microondas ou tratamento térmico apresentam novas perspectivas quanto ao estudo dos astrócitos GFAP+ (Cullen 1997). Justificam-se portanto os estudos sobre a morfologia e a distribuição de astrócitos em condições normais e em condições patológicas nas diferentes espécies.

No presente trabalho os equinos com LEM mostraram, basicamente, hipertrofia de astrócitos representada pelas maiores dimensões das estruturas celulares verificado também por outros autores, em outras lesões (Yovich 1991, Machado \& Alessi 1997, Cullen 1997). Conforme mostra o Quadro 1 , o número de células por área foi inferior nos equinos com LEM. A diminuição da densidade celular na substância branca da córtex pode estar relacionada a alterações meta- 
bólicas nas proteínas gliais à semelhança do verificado por Kimura \& Budka (1986) na encefalopatia hepática do homem. No presente trabalho, pode-se supor que estariam associadas ao curso concomitante da LEM com alterações hepáticas.

Durante o estudo, observou-se que os vasos sanguíneos dos animais com LEM apresentavam-se especialmente lesados, mostrando aparentes lesões de parede, acompanhadas de hemorragias e edema periféricos, alterações essas verificadas também por Riet-Correa et al. (1982). Nesses, havia astrócitos periféricos grandemente hipertrofiados (Fig. 5).

Importante observação foi a de que astrócitos reativos foram encontrados em sítios extra-lesões, ou seja, não só foram encontrados nas áreas com malácia, ou adjacentes, mas também em regiões cuja histologia, em cortes corados pela hematoxilina-eosina, não mostravam alterações.

Em equinos normais, na substância branca da córtex, os astrócitos fibrosos apresentavam corpo celular de pequeno diâmetro, com prolongamentos finos e longos, semelhantes aos verificados em bovinos por Machado \& Alessi (1997), no entanto com núcleo menor. A citometria empregada no presente trabalho torna mais objetivo esse tipo de análise.

Sabendo-se que a LEM surge após um período prolongado de exposição à micotoxina, sendo que, no entanto, os sintomas são de doença aguda, uma correlação entre o aparecimento das lesões vasculares e sintomas clínicos merece ser pesquisada no futuro.

Outro aspecto relevante observado, e que deve ser analisado através de estudos experimentais, é o tempo entre o início do processo de ingestão da toxina e o aparecimento de alterações nos astrócitos, pois, como se sabe, para que ocorra o processo de intoxicação, a ingestão deve ser continuada por aproximadamente um mês (Jubb \& Huxtable 1993, Mayhew 1989), com aparecimento súbito dos sintomas. De fato, os casos incluídos no presente trabalho tiveram morte entre 04 e 18 horas após o aparecimento dos sintomas clínicos. Tendo em vista as graves alterações vasculares observadas, pode-se atribuir ao edema e à hemorragia perivasculares e, talvez às lesões astrocíticas o súbito aparecimento de sinais clínicos neurológicos.

Em vista dos resultados obtidos neste trabalho, parece claro que, direta ou indiretamente, os astrócitos têm importante participação na patogenia da LEM. Muitos pontos precisam ser ainda esclarecidos, como abordado acima, mas para isso será de fundamental importância o desenvolvimento de um modelo experimental.

\section{REFERÊNCIAS}

Bignami A. 1991. Discussions in Neuroscience. Vol. 8. Elsevier Science Publishers, Amsterdam, p. 1-45.

Cameron-Curry P., Aste N., Viglietti-Panzica C. \& Panzica G.C. 1991.
Immunocytochemical distribution of glial fibrillary acidic protein in the central nervous system of the Japanese quail (Coturnix coturnix japonica). Anat. Embryol. 184:571-581.

Cullen K.M. 1997. Antigen retrieval method for glial fibrillary acidic protein immunohistochemistry: implications on neuropathological studies. Brain Pathol. 7:1179.

Eng L. F. \& Ghirnikar R.S. 1994. GFAP and astrogliosis. Brain Pathol. 4:229237.

Eng L.F., Yu A.C. \& Lee Y.L. 1992. Astrocyte response to injury, p. 353-365. In: Yu A.C.H., Hertz L., \& Norenberg M.D. (ed.) Neuronal-astrocytic Interactions: Implications for Normal and Pathological CNS Function. Progr. Brain Res. Vol. 94. Elsevier Science, Oxford.

Hajos F. \& Kalman M. 1989. Distribution of glial fibrillary acidic protein (GFAP)immunoreactive astrocytes in the rat brain. II. Mesencephalon, rhombencephalon and spinal cord. Exp. Brain Res. 78:164-173.

Jeffrey M., Wells G.A.H. \& Bridges A.W. 1990. An immunohistochemical study of the topography and cellular localization of three neural proteins in the sheep nervous system. J. Comp. Pathol. 103:23-35.

Jubb K.V.F. \& Huxtable C.R. 1993. The nervous system, p.267- 437. In: Jubb K. V. F., Kennedy P. C., Palmer N. (ed.) Pathology of Domestic Animals. Vol. 1, 4th ed. Academic Press, San Diego. 780 p.

Kalman M. \& Hajos F. 1989. Distribution of glial fibrillary acidic protein (GFAP) - immunoreactive astrocytes in the rat brain. I. Forebrain. Exp. Brain Res. 78:147-163.

Kimura T. \& Budka H. 1986. Glial fibrillary acidic protein and S-100 protein in human hepatic encephalopathy: immunocytochemical demonstration of dissociation of two glial-associated proteins. Acta Neuropathol. 70:17-21.

Lantos P.L. 1990. Cytology of the normal central nervous system, p.3-35. In: Weller R.O. (ed.) Nervous System, Muscles and Eyes. Systemic Pathology. Churchill Livingstone, Edinburgh.

Machado G.F. \& Alessi A.C. 1997. Glial fibrillary acidic protein (GFAP) immunoreactive astrocytes in the CNS of normal and rabies-infected adult cattle. I. Hippocampus and dentate gyrus. Braz. J. Vet. Res. Anim. Sci. 34. (In press)

Malhotra S.K., Shnitka T.K. \& Elbrink J. 1990. Reactive astrocytes - a review. Cytobios 61:133-160.

Mayhew I.G. 1989. Large Animal Neurology. Lea \& Febiger, Philadelphia.

McDermott K.W.G. \& Lantos P.L. 1989. The distribution of glial fibrillary acidic protein and vimentin in postnatal marmoset (Callithrix jacchus) brain. Dev. Brain Res. 45:169-177.

Montgomery D. L. 1994. Astrocytes: form, functions and roles in diseases. Vet. Pathol. 31:145-167.

Pekny M., Leveen M.P., Eliasson C., Berthold C., Westermark B. \& Betsholtx C. 1995. Mice lacking glial fibrillary acidic protein display astrocytes devoid of intermediate filaments but develop and reproduce normally. The EMBO Journal 14:1590-1598.

Privat A., Gimenez-Ribotta M. \& Ridet J.L. 1995. Morphology of astrocytes, p. 3-22. In: Kettenmann H. \& Ramson B.R. (ed.) Neuroglia. Oxford University Press, Oxford.

Riet-Correa F., Meirelles M.A., Soares J.M., Machado J.J. \& Zambrano A.F. 1982. Leucoencefalomalácia em equinos associada à ingestão de milho mofado. Pesq. Vet. Bras. 2(1):27-30.

Yovich J.V., LeCouteur R.A., Gould D.H. 1991. Chronic cervical compressive myelopathy in horses: patterns of astrocytosis in the spinal cord. Aust. Vet. J. 68(10):334-337. 